\title{
DUDS kursus og mødekalender efteråret 2015.
}

Bemærk DUDS Efterårsmøde.

Find programmer og tilmeldings information på de enkelte begivenheder på duds. $\mathrm{dk}$

\section{4. september 2015}

$\nabla$

Kursus: 32. intro-kursus i akut abdominal ultralydskanning - inkl. FAST og E-FAST skanning. Indhold: Introduktion til ultralyd og skanning af de mest vagtrelevante og almindelige akutte tilstande i abdomen. Herunder introduktion til FAST og Extended FAST traume-algoritmen.

Sted: Rigshospitalet. Pris: $2000 \mathrm{kr}$ Kursusledelse: Kristina R. Nielsen, Caroline Ewertsen, Kristoffer L. Hansen, Lars B. Svendsen, Jens Hillingsøe

\section{4. - 16. september 2015 \\ $\nabla$}

Kursus: DUDS basiskursus. EFSUMB’s level 1 kursus. $18 \mathrm{CME}$

Indhold: Ultralydfysik, ultralydskanning af abdomen. Introduktion til skanning af vener, arterier, mamma, gyn/obs, scrotum, intervention, ansamlinger/traumer (FAST), anæstesiologisk/thorax (FATE), hjerte, muskuloskeletal og hals. Samt 2 x 3 timers praktiske øvelser.

Sted: Herlev Hospital. Pris: $4.150 \mathrm{kr}$. Kursusledelse: Overlægerne Bjørn Skjoldbye og Christina Kinnander.

\section{3. september 2015 \\ $\nabla$}

Kursus: Basalkursus i Doppler-ultralyd Indhold: Introduktionskursus til til Doppler ultralyd. Kurset indeholder teori, organ-specifikke foredrag samt hands-on. Sted: Park Allé 295, Brøndby (GE Healthcare A/S) Pris: $1800 \mathrm{kr}$

Kursusledelse: Caroline Ewertsen, Kristoffer L. Hansen og Kristina Rue Nielsen

\section{4. september 2015}

Kursus: Introduktion til Interventionel ultralyd

Indhold: Principper og praktiske øvelser i ultralydvejledt intervention - biopsi, drænage, kateteranlæggelse mm.

Sted: Drejergaarden, Hvalsø

Kursusledelse: overlæge Torben Larsen

\section{Oktober 2015 (kl 13-16) DUDS efterårsmøde , Aarhus $\nabla$}

Sted: Auditorium 1, Aarhus Universitetshospital, THG

Tilmelding til sekretær Gitte Olin Overgaard (Mail: gittover@rm.dk Tlf: 784624 35)

\section{6. - 8. november 2015. Euroson 2015 \\ $\nabla$}

Sted: Athen, Grækenland
Andre kurser anbefalet af DUDS $\nabla$

9. september 2015 USabcd Course of Basic FATE, Aarhus

9. september 2015 USabcd Course of Advanced FATE, Aarhus

10. september 2015 USabcd Course of Basic LUNG US \& FAST, Aarhus

16. september 2015 Uddannelsesforløb i basal ultralydsvejledt intervention, Odense

1. - 2. oktober 2015 Course in Diagnostic Lung Ultrasound, Odense

5. november 2015 USabcd Course of Basic FATE, Copenhagen

5. november 2015 USabcd Course of Advanced FATE, Copenhagen

6. november 2015 USabcd Course of Basic LUNG US \& FAST, Copenhagen

9. november 2015 USabcd Course of Basic US Guided Regional Anaesthesia, Copenhagen

9. november 2015 USabcd Course of Advanced US Guided Regional Anaesthesia, Copenhagen

11. november 2015 USabcd Course of Basic US Guided Regional Anaesthesia, Aarhus

11. november 2015 USabcd Course of Advanced US Guided Regional Anaesthesia, Aarhus

18-19. november 2015 Uddannelsesforløb i akut medicinsk ultralydskanning, Odense

18-19. januar 2016 Kursus i Muskuloskeletal Ultralyd, Skejby 